\title{
Virtual Reality Full Immersion Techniques for Enhancing Workers Performance, 20 years Later: A Review and a Reformulation
}

\author{
Luis Alfaro ${ }^{1}$, Claudia Rivera ${ }^{2}$, Jorge Luna-Urquizo ${ }^{3}$, Sofía Alfaro ${ }^{4}$, Francisco Fialho ${ }^{5}$ \\ Universidad Nacional de San Agustín de Arequipa ${ }^{1,2,3,4}$ \\ Federal University of Santa Catarina-Florianópolis-SC ${ }^{5}$, \\ Brazil
}

\begin{abstract}
The principal aim of this article is to review and reformulate the work published by Alfaro-Casas, Bridi and Fialho [1], in 1997, about the use of virtual reality immersion techniques for enhancing workers performance'. The challenge to be solved is related to the discussion about eventual advances occurring since the publication of the original work published. The strength of the achievements relies on the open dialogue established with different human cognition theories. We consider not only Humberto Maturana and Francisco Varela autopoiesis (human biological foundations theories) but also some other approaches derived from Education Sciences and Knowledge Management. The focus is on Artificial Intelligence and the use of Immersive technologies. The state of the art is established and its contributions towards the construction of knowledge are investigated, as a means for the development of formation and capacitation activities of the workforce. The methodology used is the bibliographical revision on several databases and the search of theses in the main universities. The greatest weakness of the research relies on the fact that we limited the search to documents using the English, Spanish, or Portuguese language. Some of the open immersion problems of virtual immersion are also treated.
\end{abstract}

Keywords-Autopoiesis; knowledge construction; knowledge management; knowledge construction by full immersion in virtual reality environments

\section{INTRODUCTION}

The emergence of new technologies, the differences in countries' economic and legal environments due to the process of integrating into the global economic community together with changes in the social mentality of today, make the education received obsolete from primary school all the way to university. As time goes by, today's education turns to be insufficient to face the new situations that arise at the workplace and in everyday life. The obsolescence and the natural forgetfulness of the acquired knowledge provoke a reduction in the effectiveness of the company's work force. Physical and virtual environments present a challenge to the way we prepare this work force.

The education system, responsible for the integral formation of the individual, is not prepared to move forward adapting to technological innovations changes, and demands of the production and service processes and of the organizations themselves. The highest demands are within the industry and services, which face the question of how to make the workforce be formed and updated at the same rate.
The introduction of new technologies and innovations in the production process are altering not only the way of performing tasks in the company, but also the way of understanding and organizing the work, for whose development types of tacit and explicit knowledge are required [2]. The instruction or training in the traditional canons carried out within mass production systems is no longer sufficient and does not capture contemporary company staff formation needs such as: knowledge creation, knowledge management, services management, production, extraction, etc. At the same time, the highly rotating nature and the growing diversity of the workforce require new formation and training approaches where the new paradigm is learning while working.

Learning in organizations aims to improve the performance of the workforce, which is reflected in value: better products and services, low costs, a more competitive market position, greater innovation, improved productivity, increase when market sharing, etc. In the context of business, learning is the process through which workers acquire new knowledge or skills with the purpose of improving their performance.

This challenge can be covered in part by the formation and capacitation technologies associated with the Internet, such as the systems of : E-Learning, Adaptive E-Learning, M-Learning, U-Learning and especially systems based on Immersive and Augmented Reality Technologies.

The original work was published more than 20 years ago by Alfaro-Casas, Bridi and Fialho [1], considering mainly the biological bases of human cognition (autopoiesis theory), and the most important approaches on Education Sciences. We now also discuss concepts derived from Knowledge Management and Intellectual Capital ideas, whose emergence and maturity period have transformed the forms of organization management. Information and Communication technologies are elements that allow organizations to acquire competitive advantage. Likewise, it was necessary to establish the state of the art of immersive technologies, and analyze and reformulate their possibilities of application in workforce formation, capacitation and learning environments.

In this paper, Section II explores human cognition; Section III explores immersive technologies; Section IV explores and analyzes the potential of immersive technologies in the construction of knowledge; Section V discusses some virtual immersion open problems. Finally, future conclusions and recommendations for this work are established in Section VI. 


\section{Human Cognition}

In this part of the work, organization of living beings' concepts, and the concepts of plasticity, cognition, learning, and language are reviewed according to the proposal of Maturana and Varela [3], considering the reformulations proposed by subsequent authors [4], as well as other approaches derived from Education Sciences Knowledge Construction and neurosciences as well as other approaches from the organization theories tradition, such as knowledge management and intellectual capital as well as marketing, considering the points of view and requirements of these areas, whose action impacts organizations and their systems of human talent capacitation.

\section{A. Biological Bases of Human Cognition}

The concept of Autopoiesis proposed by Maturana and Varela [3], and summarized by Razzeto-Barry [4], as "An autopoietic system is a network of processes which produces all the components whose internal production is necessary to maintain the network operating as a unit", that is; It is the ability of living beings to self-produce themselves. In accordance with Dittus and Vasquez [5], "You have the idea that the nervous system is an instrument that obtains information from the environment, which is then used by living beings to build their world."

Each autopoietic unit is unique, since it is characterized by phylogenetic inheritance or Phylogeny (history of the species) defined as, the succession of organic forms that are related due to a sequence of reproductive relationships; and by the history of individual adaptations or ontogeny [6]. Ontogeny is defined as "the history of the structural change of a unit without losing its organization". At the level of a living being's organization, all organic operation is knowledge, as the aphorism says: "all doing is knowing and all-knowing is doing".

Social systems are systems of coordination of actions in language, that is, a conversation network that Maturana [7] defines as: "Flow of coordination of actions and emotions, which we, observers, distinguish as occurring between human beings who interact recurrently in language". The author also argues that "We live in communities that exist as networks of conversations, intercrossed, not intersected, of different types, that match each other in their flow through the intersection in our corporality". The author mentions the following types of conversations:

- Coordination of present and future actions.

- Complaints and apologies for agreements not taken.

- Of wishes and expectations.

- Command and obedience.

- Characterizations, attributions and evaluations.

- Complaints about unfulfilled expectations.

Consequently, different human autopoietic systems generate their own networks of conversations, which even affect their bodies. As a result, they move through these networks on a daily basis, regardless of their conscience, in domestic, educational, political, social, religious, etc. spaces, acting in tune with the actions related to these conversation systems they motivate to be and do. For Maturana [7], human relations that are not based on the acceptance of the other as "A legitimate other in coexistence" are not social relations, the author affirming that labor relations, "are not social because they are founded on the commitment to fulfill a task, and in them the fulfillment of the task is the only thing that matters".

In Flores and Terry [8], the role of the background and interpretation is highlighted while retaining the focus centered on the commitment engendered by the acts of language. These concepts are of paramount importance in the design of contemporary computer systems for the support of educational activities, which at present have involved the conception of systems that consider the Ontological level, as well as predictive and highly adaptive functions to the characteristics and profiles of the apprentices, and the same ones that have the support of the techniques and methodologies and techniques of Artificial Intelligence. A cognitive system is "a system whose organization defines a domain of interactions where it can act with relevance to the maintenance of itself, the process of cognition being the actual performance or behavior in this domain" [7]. On the other hand, for Austin [9], speech acts consist of three elementary levels:

- Locutive act: it is the idea or concept of the phrase, that is, what is said.

- Illocutive act: it is the specific intention of speech acts.

- Perlocutive act: it is the $\operatorname{effect}(s)$ that the statement produces in the receiver in a given circumstance.

Speech acts can be classified according to their intention or purpose to which they refer, as follows:

- Assertive or expository acts: the speaker denies, asserts or corrects something, with a different level of certainty.

- Management acts: the speaker tries to force the listener to execute an action.

- Commitment acts: the speaker assumes a commitment, an obligation or a purpose.

- Declarative acts: the speaker intends to change the state in which something is found.

- Expressive acts: the speaker expresses their mood.

Communication mediated by speech acts enables communication in relation to the so-called explicit knowledge, which becomes the tradition of knowledge management [10], establishing the difficulty to establish communication in relation to tacit knowledge [11]. With regard to the use of knowledge for the understanding of language, the processes involved in the acts of speech, listening and reading, have similarities; even having some different attributes. In reading, each word can be seen as a whole; however, a spoken word spreads in the environment. The word provides a more ambiguous and confusing signal than a printed text [12].

Most theories about text comprehension are also relevant for speech comprehension, as there is a lot of evidence that indicates that there is a close relationship between these two processes. It is important to establish an understanding of the mind and its realizations in the perception, learning, 
thinking and using language, considering the processes in which individuals deal with stimuli, how they organize data, how they solve problems and use verbal symbols [12].

Understanding a situation requires that the cognitive subject have a model of that situation. However, at a certain moment a model may be insufficient for the construction of certain concepts, arising from the need to resort to another model, which raises the need to propose systems that have a high degree of adaptation to the requirements of the cognitive subject, which has different learning and thinking styles, and therefore the diversity of demands for processes and resources must be recognized. Consequently, individual learning models evolve towards models with a higher level of organization and converge in the actions of business organizations in the direction of team learning.

In contemporary organizations, there are profound changes due to the increasingly growing demands, in relation to quality, productivity, innovative capacity among others, for the production of goods and the provision of services that make organizations focus on obtaining competitive advantage and generally favoring teamwork over the individual, which brings with it the requirement of establishing new ways of organizing tasks, new instruments for controlling results and new ways of successfully evaluating the management of operation processes , changes that have an impact on the training of the workforce, which presents demands for skills to acquire, often for the treatment of complex issues in short periods of time. Team learning, defined by Senge [13], as the process of alignment and capacity development, is today privileged by organizations over personal and / or individual learning systems.

Likewise, for Maturana [7], "Education is constituted in the process in which the child or the adult lives with another and when living with the other, transforms spontaneously, so that their way of living, is progressively done more congruent with another, in the living space". Education occurs, therefore, all the time, in a reciprocal way, as a contingent structural transformation to a history in living together in which it turns out that people learn to live together in a way that is configured, according to the living of the community where they live. Education as an "educational system," shapes a world, and students confirm in their living the world they lived by being educated in education.

The perspective of teaching in the biology of love [14], considers that many of the different forms of bodily dynamics, which emerged with the evolutionary history that gave rise to humanity, reappear in the ontogeny of the child's physical and mental development. Children's free play, when emerging without the influence of adults, is organized spontaneously based on innate forms of actions, movements and perceptions, which come from human evolutionary history or phylogeny. Thus, the forms of children's free play are not arbitrary; they are forms of body dynamics that are linked to ancestral behavioral territories, to expressions and connections between the living being and its environment, and whose current forms are just transformations of archaic forms.

These concepts have given rise to what is now known as the Biology of knowledge, an approach in which, as human beings are like other living beings, operationally closed and engaging with others through linguistic mediation, -that is, they live in language- they learn, relate, coordinate with others and live experiences in the emotional world in which they are immersed. Finally, in relation to training in the context of knowledge biology, these ideas point to the use of the new technologies such as ICTs, VR, Augmented Reality and Social networks, that meet the demands of education and training of organizations and the workforce.

\section{B. Approaches from the Perspective of Education Sciences}

Regarding the explanation of the development of human autopoietic units, it can be said that various approaches try to explain this, and some theorists propose educational philosophies or currents, which are briefly explained as follows:

1) Constructivist Perspective: The works of Gestalt psychologists, Piaget [15], Vygotsky [16], Bruner Bartlett [17] and Dewey [18], emphasize the active construction of meaning by the individual. This approach, instead of postulating the memorization of information, postulates the creation of meaning and construction of knowledge.

A constructivist point of view makes us recognize the potential of an 'invented reality', strongly influenced by the individual's capacity for perception and action [19]. The epistemological point of view identifies the nature of knowledge as caused primarily by a process of construction and interpretation that is based on personal experiences, mental structures and perceptual mechanisms, which are deeply rooted in the individual's corporeity and in real or simulated contexts.

Many constructivist perspectives consider the social context as one of the fundamental factors of knowledge that people acquire regarding themselves and the world. Various theories that also try to explain the information processing carried out by the human autopoietic unit, the representation of knowledge in memory, and the individual differences between students.

2) Constructionism is one of the contemporary dogmas in education theory: According to this approach, learners assimilate knowledge through constructive tasks. The goal of the approach is to foster creativity and motivate learning through activities. Learning is most effective when placed in an activity, passively received [20]. For Bruckman [21], the term "constructionism", involves two types of construction:

- Learning is an active process, in which people actively build their knowledge and experiences in the world (idea based on the theories of J. Piaget).

- The idea that people build new knowledge when they are involved in the construction of products of personal significance. What is important is that they are actively involved in the creation of something that is meaningful to themselves and others in their environment.

Finally, Winn [22] points out that Immersion in a virtual world allows us to construct knowledge from direct experience, not from descriptions of experience. Any learning that is mediated by a symbol system, whether text, spoken language, or computer, is inevitably a reflection of someone else's experience not our own.

In Maturana [23], it is suggested that intelligence or "plasticity", comes from the greater or lesser capacity of organisms 
to adapt to their environment. Immersive VR can be one of the emerging technologies, which allow to recreate real or virtual environments, with the advantage of being able to abstract and synthesize some variables, such as time, and space among others, that will allow unique and original experiences in First person, that is to say without symbolic mediation and therefore reflection, enabling formation and learning that involve tacit and explicit knowledge, in a direct, original, unique and unforgettable way. Next, immersive technologies and their application possibilities will be explored, for the construction of first-person learning environments that generate rich and lasting personalized experiences.

\section{The Perspective of Knowledge Management and Intellec- tual Capital}

Knowledge is interpreted as the fact of knowing, mastering certain activity, situation, task, etc., based on the information, experience, and beliefs that the individual possesses, within a given environment [10]. Many authors claim that the only source of competitive advantage is knowledge, and knowledge is the only significant resource, being more than a simple resource in the equation of the factors of production, land, labor and capital [24]. The industries that have managed to grow in the last 40 years have grown because they were structured around knowledge and information. In this scenario, the center of gravity in employment is rapidly moving from manual and administrative work to the knowledgeable employee [25]. There is another way of understanding knowledge, associated with the ability to respond quickly to customers, create new markets, develop new products and master new technologies [26]. The company that creates knowledge as a place where "inventing new knowledge is not a specialized activity (...) but a way of acting; a way of being where everyone can be considered as a knowledge worker. There is a relationship between organizational learning and continuous improvement.

On the other hand, tacit knowledge is knowledge hidden from the consciousness of the knower. Tacit knowledge resides in the human brain and cannot be easily captured or codified [27]. All our knowledge rests in a tacit dimension. Tacit knowledge expresses itself in human actions in form of evaluations, attitudes, points of view, competences, experiences and skills stored so deep in the worldview of an individual that it is often taken for granted [11]. It can be observed through action.

On the other side, the Explicit Knowledge can be articulated in formal language and transmitted amongst individuals. Explicit Knowledge implies factual statements about such matters as material properties, technical information and tool characteristics [28]. Thus, explicit knowledge can be compressed into a few summary symbols that can be encoded by language in written words and / or machine. By its very nature, explicit knowledge is capable of being captured and widely distributed throughout the organization. In the organizational field, the following types of learning are established [12]:

- Individual learning can be understood as a cycle in which people assimilate new data, information, reflect with past experiences, reach a conclusion or a conception of new knowledge which is used to achieve a new objective. Thus, learning is based on research and problem solving. The processes in which learning happens have a predominant role, so the central point of teaching consists of process and not learning products.

- Team learning [29], is defined as the process of alignment and development of a team's ability to create the results that its members really want through the development of coordinated actions, establishing the open flow of knowledge, conversations and active participation in the elaboration of the logic to be followed, where teams are the largest unit of learning. The skills developed by a group can establish a pattern for organizational learning, so they have three critical dimensions [12].

1) Teams need to learn to use the potential of many minds, in order to have greater intelligence than a single mind.

2) Each team member acts in a way that complements the actions of the others.

3) A team that learns, stimulates other teams through the dissemination of team learning practices and skills more widely.

In this case, the introduction of immersive technologies allow incorporating apprentices and team members, whether human or virtual, who are able to use avatars that assume the role of apprentices, masters, team members, or even specialists who have a broad repertoire of explicit and tacit knowledge. The existence of the relationship between Organizational Knowledge Management and the competitive advantage goes through various aspects, but mainly through people and their knowledge. Other aspects are: Knowledge Engineering, and the technology integration between knowledge management and the organizational learning process areas. Each of these three dimensions can be worked on, from the perspective of the generation, preservation and dissemination of knowledge, in order to create a competitive advantage for the company.

\section{IMMERSIVE TECHNOLOGIES}

\section{A. Virtual Reality (VR)}

VR is defined as [30]: "A three-dimensional environment synthesized by computer, in which the plurality of human participants, with appropriate interfaces, can establish contact or interact with representations of other humans from the past, present, and fictional and / or invented creatures". For Yoh [31], VR is a technology that simulates reality through software, recreating the effect, essence and sensations of a given situation that does not materialize in real events.

According to Gonzales and Lanier [32], VR refers to completely artificial environment generated by computer, in which the user experiences an immersive and interactive feeling without having any eye contact with their real environment. This virtual world can be the result of a process of digital creation, being able to place the user in a totally fictional world in which the physical and perceptual laws differ completely from their real world. In addition, in the latest systems it is possible to make certain displacements within this virtual world, beyond simple head movements. It is also possible to move the user to a point in real-time, but different from that of the user, previously registered in a $360^{\circ}$ recording, so that it can be reproduced as a virtual deferred experience. 
As a variant, is the real-time broadcast or streaming of a recording made anywhere in the world, so that a user can view it as a virtual world elsewhere, and interact with the source through a digital audio connection over the Internet. All these variants allow the user to live a truly immersive experience in a real or fictional world; however, the fact of not being able to observe one's own anatomy within the virtual world subtracts the system from some realism, limiting perception regarding the surrounding reality. Similarly, VR systems excessively evade the user from their immediate environment, producing a certain feeling of dizziness after a prolonged period of use. It is currently applied in entertainment, education [33], advertising, marketing, Knowledge Management, etc.

In VR there are two types of applications: the "Immersive", where the user is within the simulation, and the "NonImmersive", in which the user is outside [34]. An important feature of immersive VR is 'Stereoscopy', which allows users to distinguish the depth of the objects they observe, adapting to their natural way of seeing the surrounding environment . This is generated by a binocular vision, creating the illusion of perceiving objects in 3D from two images that are taken from different positions, recreating the human 3D vision [35].

VR has evolved rapidly. At the beginning it could only be used by scientific-military laboratories at an excessive cost, but it is now possible to have VR equipment at an affordable cost. It is precisely the special characteristics of these devices which are the key components for the design of the proposed architecture located in a virtual environment.

\section{B. $2 D, 3 D$ and $R V$ Viewing Modes}

For Zohra [36], there are different approaches to the use of 2D, 3D and RV representations in relation to the Visualization of Information, presenting a brief description of each:

- 2D uses only two dimensions; the graphics are flat, it stands out for its simplicity, clarity and precision when displaying information. A large part of the actual interfaces are designed for this type of representation. In most, the interaction is traditional, using the most common interaction techniques such as: Select and Zoom.

- $3 \mathrm{D}$, is the way in which an object is represented in a three-dimensional space, mapped on a twodimensional surface. The visual perception of $3 \mathrm{D}$ it is achieved through the use of visual elements of depth such as lights, shadows and perspectives, but the final appreciation is flat. These environments facilitate navigation, however, they result only from an extension of the interaction techniques in 2D environments, which use visual effects to generate the illusion of volume.

- VR is a technique that enables immersion in a multimodal viewing environment, which also uses stereoscopic images to improve depth perception, making possible to perceive 3D as in the real world. VR environments allow the user to be immersed, causing the interaction to be different. Unlike the visualization techniques in 2D and 3D, VR techniques have not been thoroughly studied or standardized. An example of VR interaction techniques is: Direct manipulation, in which a virtual hand is available to interact directly with the visualization.

Between $60 \%$ and $80 \%$ of the objects of study to be viewed are of $3 \mathrm{D}$, but most of the visual representations implemented are in 2D, followed by those made in 3D, because those conceived in VR are currently very scarce [37]. The debate regarding the quality between $2 \mathrm{D}$ and $3 \mathrm{D}$ is still extensive, but many authors reach the consensus that $2 \mathrm{D}$ are the most appropriate if accuracy and better interpretation are desired; instead, 3D are useful if better navigation and relative positioning are preferred [38]. Fig. 1 shows an example of the three types of environments.

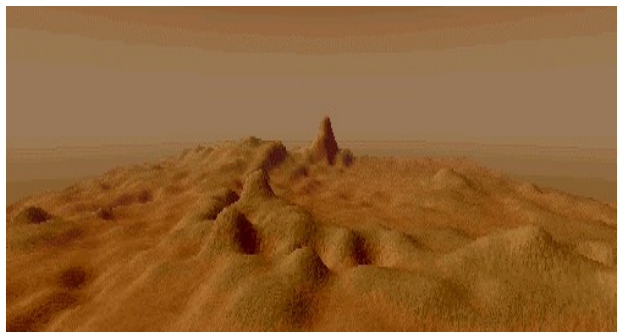

(a) 2D Image

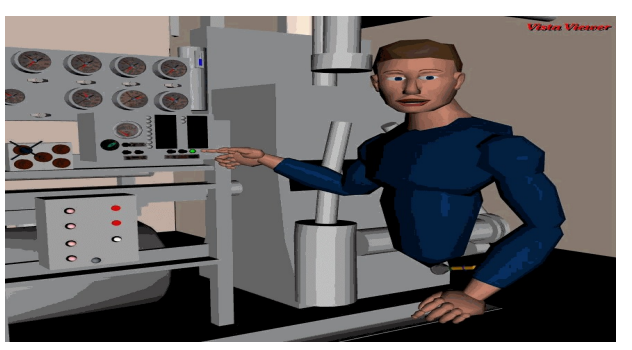

(b) Scanner captures 3D image

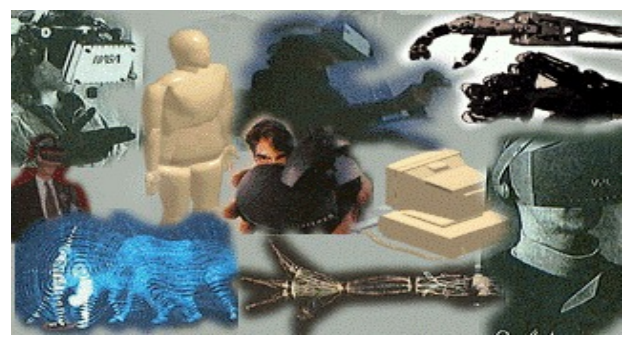

(c) Immersive VR Image Composition

Fig. 1. Interaction device prototypes. Source: [30]

\section{Immersion}

This is a feature of VR in which users are in a simulated environment. An immersive VR system seeks the user to lose contact with reality by exclusively perceiving the stimuli of the virtual world. However, the immersion achieved so far in VR systems is restricted only to spatial immersion; that is, the perception of being physically present in a virtual world [39]. Psotka [33], states that the fact that a user is in a simulated virtual environment has a huge emotional factor that facilitates cognition and improves information retention, because the user feels that they are part of software. In addition, immersion broadens the user's range of vision, including their displace- 
ment (very useful in virtual tours) and collaboration (used for manufacturing applications) [40] [41].

Slater [42] distinguishes two ways of experiencing immersive VR: an HMD VR helmet (acronym for head-mounted display) and a three-dimensional cave-like environment . For this purpose, immersion has been achieved through different configurations, for example, a single giant screen may be used as well as anaglyph lenses. Another configuration is that of a CAVE environment, which consists of four or 6 walls of almost $3 \mathrm{~m} 3$, which function as stereo projection screens. The images are determined as a head tracking function so that, at least with respect to the visual system, participants can physically move through a limited space and orient their head arbitrarily to be able to perceive. Usually, the audio is delivered by a set of speakers in discrete positions around the CAVE [43].

In this investigation, the immersion will be used based on a VR helmet, which is one of the most comfortable compared to the others and because it gives a greater sense of presence that helps memory and other cognitive processes [44]. But one of the main drawbacks of this configuration is that it can cause dizziness in certain users.

\section{Immersive $R V$ Devices}

Over the years, different VR devices have emerged, most of them manufactured for a specific purpose. In this investigation, in relation to the proposed system architecture, the hardware configuration would consist of the following devices: 'Oculus Rift', 'Leap Motion', and 'Oculus Go'. Fig. 2 shows the main VR viewers in the market. Oculus Rift (Fig. 2(a)) is the first to include a series of improvements such as stereoscopy and low latency in the refresh rate. HoloLens (Fig. 2(b)) experiences how to mix VR and augmented reality, in addition to creating the first holographic processor. PlayStation VR (Fig. 2(c)) is created for entertainment purposes and noted for its sophisticated design. HTC Vive (Fig. 2(d)) on the contrary, stands out for its good performance and development platform. Gear VR (Fig. 2(e)) uses VR with a wireless approach for which it requires a smartphone. Oculus Go (Fig. 2(f)) is an alternative similar to the previous one, with the difference that its cost is much lower.

In Table I, these viewers are compared considering the main technical characteristics such as: Screen resolution, refresh rate, viewing angle and price.

TABLE I. COMPARISON OF VIEWERS CONSIDERING TECHNICAL ATTRIBUTES AND COSTS. SOURCE: AdAPTED FROM [37]

\begin{tabular}{|l|c|c|c|r|}
\hline Visor & Resolution & Refresh rate & Vision angle & Price \$ \\
\hline Oculus Rift & $2160 \times 1200$ & $90 \mathrm{~Hz}$. & $110^{\circ}$ & 700.00 \\
\hline Hololens & $1920 \times 1080$ & $120 \mathrm{~Hz}$. & $110^{\circ}$ & $3,000.00$ \\
\hline PlayStation VR & $1920 \times 1080$ & $120 \mathrm{~Hz}$. & $100^{\circ}$ & 400.00 \\
\hline HTC Vive & $2160 \times 1200$ & $90 \mathrm{~Hz}$. & $110^{\circ}$ & 900.00 \\
\hline Gear VR & $2560 \times 1440$ & $60 \mathrm{~Hz}$. & $96^{\circ}$ & 100.00 \\
\hline CardBoard & Variable & Var & $90^{\circ}$ & 5.00 \\
\hline Oculus GO & $2560 \times 1440$ & $72-60 \mathrm{~Hz}$. & $110^{\circ}$ & 169.00 \\
\hline
\end{tabular}

\section{E. Natural User Interfaces (NUI)}

NUI are those interfaces in which user interaction is natural, common and familiar [45]. That is why its design

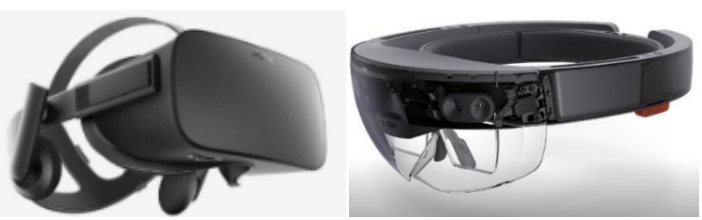

(a)

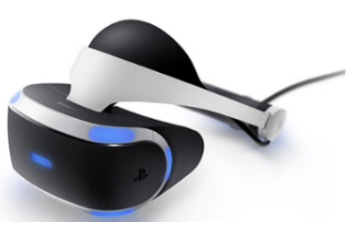

(c)

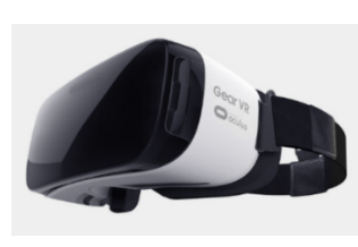

(e) (b)

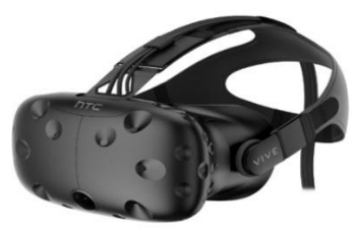

(d)
Fig. 2. Interaction device prototypes. Source: [37]

implies the use of new devices that allow this interaction, which goes beyond the use of the keyboard and mouse. These new generations of devices allow the use of the software by gestures, touch, body movement, voice, etc. Examples of NUI devices are Kinect [46], [47], that copy the movements of the body and send them to a virtual avatar. This device allows the user to control the application without requiring another peripheral, because it also allows voice recognition for command interpretation. The great utility of using NUI is that they are intuitive and easy to handle. For example, for nonnative digital people, learning how to use the mouse is quite complicated, but using Kinect is relatively easy for any user. It is this ease of use which is desired in any user interface, but NUI should not be applied to any application; for example, it would be difficult to use Kinect to operate a word processor.

The recent development of input peripherals is changing the way of interaction with digital screens, the mouse and keyboard, and these are being replaced by tactile interfaces based on body movement [48]. These new ways of interacting are part of the evolution of the interfaces, which throughout the history of computing have evolved, changed and diversified. The term NUI was coined by Mann [49], who explores new forms of computer human interaction, emerging a variety of investigations that focus on new fields of application.

Finally, the NUI, constitute a revolution in the world of computing, not because they will replace the existing and widely used traditional interfaces, but because they enable the creation of new types of applications and new forms of original and novel interactions liable to be applied in Production, Administration, Marketing, etc. 


\section{F. Natural Devices Interaction}

Fig. 3 show the main devices necessary for the creation of NUI. Kinect (Fig. 3(a)), is the first to appear in the market, created for entertainment purposes for games controlled through transduction, but then used for more advanced applications. Nimble (Fig. 3(b)), focuses only on hand recognition. Manus (Fig. 3(c)), unlike the others, uses motion sensors built into gloves.

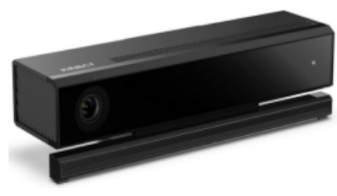

(a)

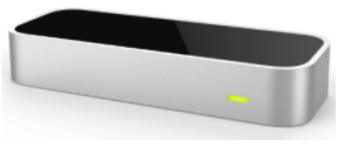

(b)

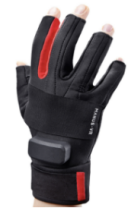

(c)

Fig. 3. Natural Devices Interaction. Source: [37]

The historical review and the establishment of the state of the art allow us to glimpse the enormous potential of the resources and elements of immersive technologies, whose use in marketing strategies will allow innovative approaches.

\section{KNOWLEDGE CONSTRUCTION BY IMMERSION IN IMMERSIVE TECHNOLOGIES}

Constructivist learning supported by technology, focuses on how representations and applications can mediate interactions between learners and natural and social phenomena. The key to VR compatibility with constructivism relies on the notion of immersion. First-person experiences consider the treatment of activities in the world and in learning about this. First-person experiences occur when interaction with the world does not involve reflection of consciousness or use of symbols. According to the constructivist theory and with the perspectives of the Biology of Knowledge, the construction of knowledge arises from first-person experiences, which can never be entirely shared. Immersive VR allows first-person experiences through the elimination of interfaces that act in the user-computer interaction [50]. In this, the contribution of the VR is unique, since it allows a synthetic experience to capture the essence of what it really is. The meaning for the person approaching in order to know the world.

Immersion in a virtual world allows to build knowledge from a direct experience, not from a description of the experience. Any learning that is mediated by a system of symbols, whether textual, spoken language or by a computer, is inevitably a reflection of the experience of the other. Any communication in which we use a symbolic system to communicate to another person, can never allow that person to know that world as we know it. The Constructivist theory describes how first-person worlds become internalized and argues that any imposition of symbolic representations motivated by communication requires negotiation in relation to the dominant meaning for commitment [51]. However, in the multi-participant VR, in which a group of participants is immersed in the same world at the same time, it will allow the negotiation of meaning to be established, and communication between participants may be required.

Immersion in VR environments, allows a type of interaction with the objects with which participants interact, similar to the interaction that takes place in the real world. Biology of Knowledge, Constructivism and the so-called "Tacit Knowledge" concept (derived from Knowledge Management Theory), sustain that cognition is non-symbolic and learning is "linked" stated by Maturana [52], "learning occurs when behavior of an organism varies during its ontogeny, in a manner consistent with the variations of the environment, which it does following a contingent course in its interactions with it". Likewise, the organism does not construct a representation of the environment, nor does it find a proper behavior for it. For it to operate, there is no medium, there are no things to be remembered or memory, only a structural dance in the present, which follows a course consistent with the structural dance of the medium. Otherwise the organism disintegrates. Likewise, learning is action-oriented through interaction with the virtual world, being in that moment that knowledge is built. Papert [20], [21] uses the word "constructionism" to describe the construction of knowledge that arises from physical interaction with objects in the world. Immersive VR allows physical and perceptual interactions to occur in that synthesized world.

VR extension can simulate the real world. This allows workforce formation and capacitation inside the context they are supposed to apply the acquired knowledge. In order to do this, environments must be proposed and designed following Anchored Instruction [53] perspective, which enable experiences with better results than that obtained when learning out of context. Learning scenarios in factories, respecting logistics and supply operations, simulating experiential marketing actions, supporting Tacit and Explicit Knowledge management, among others, will enable the tuning of learning activities, for example, within the framework of Project Based Learning (PBL) [54], allowing immersions in simulated synthetic environments, to consider aspects of reality or fiction, by modifying some variables such as time, dimensions, costs, Etc. Due to the fact that the virtual environment is computed from data, this allows the participant three kinds of knowledge building experiences that are not available in the real world; however, it can have enormous potential in workforce formation and capacitation: These concepts are called "Dimension", "Transduction" and "Reification" [50].

The immersion in $\mathrm{RV}$, allows radical changes in the dimensions in relation to the participant and the virtual objects. In the real world, when approaching an object, it appears larger and as it moves away, it decreases in size, there are limits to both ends. There is a point at which there can be no closer approximation to the physical object and this point marks the maximum apparent dimension of an object. In the same way, there is a point at which the object disappears when distance is taken from it. In a virtual world, otherwise, one can infinitely approach or move away from objects, allowing large changes in dimension. For example, before hitting the virtual wall, the subject could obtain approximations, so that 
smaller and smaller details of the material from which it is constituted, the cellular structures of a wooden panel can be shown and visualized, even the molecules and atoms of which it is basically composed. From another perspective, you can expand the vision of a wall, the exterior of a house, a country or even the planet or the galaxy, all this without violating any of the four conditions for immersion. The advantages of such changes in the dimension for education are significant. Finally, it is possible for the cognitive subject to have a notion of the relative dimensions and distances between the planets of the solar system through flights from one to another. These experiences will depend largely on the metaphors proposed by the designers of these environments.

Likewise, the immersion and interaction technology used in 3D VR systems allows us to overcome didactic obstacles present in topics that contain, due to their nature, situations of danger or potential risk for students [55]; for example, places of difficult access or that are dangerous can be known easily and safely without the need to physically move to them, solving some problems such as: security issues, industry confidentiality restrictions, long distance trips from work or education centers, which cause transfer costs.

$\mathrm{VR}$, in general, is widely used in the fields of education and formation due to its potentials in stimulating interactivity [56] and motivation [57][58]. Furthermore, it offers an ideal manner to approach, study and remember new knowledge for all those who prefer this learning style [59].

On the other hand, the primary motor cortex is the main source of neural signals that control movement, whereas the premotor cortex and supplementary motor appear to be involved in the preparation and planning of movement. Many more parts are involved in motion and communicate through neural signals. The most interesting part is the cerebellum, meaning "small brain", which it seems to be a special processing unit that is mostly devoted to motion, but is also involved in functions such as attention and language. Damage to the cerebellum has been widely seen to affect motor control and learning of new motor programs. One of the most relevant uses of the cerebellum for VR [60], is in learning sensorimotor relationships, which become encoded into a motor program. All body motions involve some kind of sensory feedback. The most common example is hand-eye coordination; however, even if you move your arms with your eyes closed, proprioception provides information in the form of reference copies of the motor signals. Developing a tight connection between motor control signals and sensory and perceptual signals is crucial to many tasks.

The transducers, similar to eyephones and earphones are used in VR hardware to present information to participants, and to convert participants behavior into software interpretation commands. Transducers are devices that convert information not available to our senses in other ways that are. Changes in size and transduction for access to cognitive subjects to first-person experiences could not be made otherwise. Some of these experiences arise from simulations in relation to some aspects of objects and or events. Others arise from representations through the transduction of objects and events that do not have a physical form, making them perceptible to experiences or the senses, in cases such as algebraical equations, and dynamic populations among others.
"Reification" is the process of creating these perceptible forms. Reification is placed as opposed to simulation. In the simulation, the virtual world contains representations of real objects and their behaviors. Its advantage is that students can interact with them and generally, RV is a more economical alternative for building physical simulators. However, it should be noted that the power of VR can be underutilized, when used for simulation. VR is not used efficiently when it is used to create simulations that can be performed through traditional simulators.

\section{SOME Open Problems In VR IMMERSiON}

Immersion characteristics were analyzed by Postka [61], through questionnaires designed to access individual susceptibilities for immersion and how deep this experience was to the participants. In the research reported, the questions were carefully built to cover the cognitive factors mentioned in the literature as meaningful for VR environments. A five-point scale of categorical answers was used. Two psychological factors considered as dominants for predicting immersion deepth were: the imagination needed for accepting another reality (a living imaginary turns the participation integral and satisfactory) and the concentration, attention, and selfcontrol needed to exclude real world effects of distraction. The extension of the visual field in an HMO, the precision of the egocentric localization, audio precise information (synchronized with visual changes like rotations, head movements of affirmation, or accelerations), are determinant factors of an in depth immersion. A "cognitive tracking" paradigm was used to get visual-vestibular interactions. The precise synchronization of the spatial head movements and the changes in visual perspective result in a deeper immersion, even with an imprecise coupling between head movement and changes in the visual presentation [61]. Cognitive factors were grouped in two categories, immersion susceptibility and quality:

- Susceptibility depends on imagination (dreams, a gift for replacing old beliefs), a living imaginary (dreaming, previous expectations about VR environments), concentration and attention (attention filtering, cognitive conflict by two recursive immersions, spatial navigation), and self-control (active participation and catharsis).

- Quality depends on the environmental resources provided by the VR immersion (object persistence, sensorial perfection, interactivity, environment realism, delays, visual field, localization of the ego center or corporal image, pleasure and satisfaction with the new experience), distractions due to the real environment (noise, tactile presence, tiredness, irritation with the equipment, similarity between real and virtual world), psychological effects (simulator disturbances, disorientation after immersion), and other effects (preference for a lonely immersion, surprise when the HMD is removed). Movements in the virtual environment, at the present stage of technology can originate several errors (an extremely slow answer, failures). The main causes of movement errors are: imprecise scenery for the inter ocular distance, absence of convergence and accommodation signals, lack of good texture gradients for depth and improperly designed models. They are 
easily perceived and remain a disturbance factor in several VR applications.

Psotka [24] reports that with an exhibition vision greater than $60^{\circ}$ (field of view, FOV), several individuals relate some level of discomfort although not mentioning nausea, (fields of vision less than $60^{\circ} \mathrm{FOV}$, produce a poor sense of immersion. Nowadays a FOV $210^{\circ}$ horizontal and $130^{\circ}$ vertical is reached). The relationship between behavior and the study about self-oriented emotions are strongly dependent on FOV. The most influent requirement for immersion is a solid coupling between head movement and visual exhibition. Data input delays in visual exhibition using HMD immersion results in a brisk interruption of spatial orientation and a poor immersion experience [24].

Immersion can be understood as a dual phenomenon; from one side it depends on subconscious skills and, from the other side it depends on our voluntary attention abilities that depend on self-control, self-consciousness, will, expectations, etc. Those two factors (implicit versus conscious immersion control) are captured by the found correlation that immersion is more complete in someone that is able to have dreams in colours [24]. How those two components interact is a mystery. The implicit and conscious components seem to perform different things without affecting one another directly. These factors appear so briskly that they make themselves visible in all three sets of correlation: in the susceptibility factors, in the immersion factors, and in their inter correlations. Implicit factors present a kind of dominance. If the delay between the iteraction and the visual feedback of a movement perceived by a hand in VR is too big, there is no image filtering technique sufficient to reduce this delay, disturbance occurs. When the visual system indicates that the egocentric or corporal image is in a certain location but the kinesthetic centers are in some near place, there is no way to integrate these two positions. A long time may be necessary for the learning and adaptation processes to change the cognitive machinery [61].

Despite the important advances, the treatment of the cognitive and perceptual components of immersion is a longterm challenge, which is required for capacitation and formation, and for educational proposals, because it is known that many of the cognitive representations are in the form of mental models for the understanding of complex systems. Research in VR should be focused on transforming knowledge into experience and turning education, formation and capacitation into more direct and effective action [10]. Instead of supplying access to a greater cyberspace, the equipment used nowadays is still causing sensations like claustrophobia, nausea and confusion after the experiment [10].

For La Valle [60], signals from multiple senses and proprioception are being processed and combined with our experiences by our neural structures throughout our lives. In ordinary life, without VR or drugs, our brains interpret these combinations of inputs in coherent, consistent, and familiar ways. Any attempt to interfere with these operations is likely to cause a mismatch among the data from our senses. The brain may react in a variety of ways. It could be the case that we are not consciously aware of the conflict, but we may become fatigued or develop a headache. Even worse, we could develop symptoms of dizziness or nausea. In other cases, the brain might react by making us so consciously aware of the conflict that we immediately understand that the experience is artificial. This would correspond to a case in which the VR fails to convince people that they are present in a virtual world.

While it is true that since the publication of the original article to the present, many of these problems have been overcome or their effects have been reduced, mainly due to innovative approaches and contemporary technological resources applied in the design and development of different elements of hardware and software of immersive technologies, it is seen that efforts and constant research in the area, must achieve improvements and optimizations that are increasingly important, envisioning the improvement of quality, usability and ergonomic attributes of different devices in humanmachine interaction. However, some of these problems must be considered in the analysis and development of systems for education, training and human talent, since the characteristics and particularities of different work environments, the diversity of learning styles and thinking of apprentices, as well as the different educational approaches and conceptions of resources, generate demands for systems and learning objects, with a high degree of adaptability to individual profiles, interests and characteristics of cognitive subjects. The holistic incorporation of some characteristics of the different approaches reviewed, such as the Biology of Cognition, Educational Sciences and especially of Knowledge Management, would make possible the construction of useful environments for a diversity of scenarios and cognoscent subjects.

\section{CONCLUSION AND RECOMMENDATIONS}

- The biology of Cognition that establishes the biological basis of Human Cognition, as well as approaches from the educational and Knowledge Management perspective, suggest that intelligence or "plasticity", come from the greater or lesser capacity of organisms to adapt to their environment. Immersive VR can be one of the technologies that allow recreating synthesized real or virtual environments to achieve first-person experiences; that is, without symbolic mediation and therefore reflection, with a high degree of adaptation to profiles and particularities of the cognitive subject, enabling formation and capacitation that involve tacit and explicit knowledge in a direct, original, personalized, unique and unforgettable way.

- The materialization of the perceptual and cognitive components of immersion seems to be a long and arduous task but, the results will compensate all the effort. It is particularly satisfactory for formation and educational proposals because we already know that most of the cognitive representations assume the form of mental models that are used for understanding complex systems. VR promises to turn education and formation in tools that will be much more direct and effective than nowadays.

- The state of the art of the biological foundations of cognition, of the different approaches to education and of the immersive VR have been established, allowing to know the enormous potential of this emerging technology, which would make it possible to innovate 
the forms and methodologies for Innovative formation and capacitation practices, since experiences close to reality can be considered, when using metaphors that include multisensory perceptions, for first-person learning experiences.

- The creation of intelligent formation and capacitation systems is a complex issue that demands the participation of various sources of experience. That is why, for the development of this kind of systems, it is required to employ the method of work in multidisciplinary teams, which include specialists in the fields of pedagogy, psychology, neurosciences, specialists in the domain of knowledge that It aims to teach, technicians in graphic, artistic, computer, multimedia, VR and project management.

- It is essential to insist on a continuous, open and personalized education that allows the individual to update and adapt knowledge throughout their professional life.

- It is important to employ AI approaches, in order to provide formation and capacitation with some adaptive characteristics, derived from user profiles.

\section{ACKNOWLEDGMENT}

The authors would like to thanks to Saint Augustin National University (UNSA) - Arequipa - Perú and the Federal University of Santa Catarina - Florianópolis - Brazil

\section{REFERENCES}

[1] L. Alfaro-Casas. L. Bridi. F. Fialho. Virtual reality full immersion techniques for enhancing workers performance. L. M. Camarinha-Matos (ed.), Re-engineering for Sustainable Industrial Production (C) Springer Science+Business Media Dordrecht 1997

[2] A. Uriarte. "Introduction to Knowledge Management Copyright. ASEAN Foundation 2008. ISBN No. 978 - 979 - 19684 - 0 - 9

[3] H. Maturana; F. Varela. De máquinas y seres vivos - una teoría sobre la organización biológica. Chile. Editorial Universitaria S.A. 1972. 121 p.

[4] P. Razeto-Barry. Autopoiesis 40 years Later. A Review and a Reformulation. In Origins of Life 42(6), 2012. DOI: 10.1007/s11084-012-9297

[5] Dittus, R. y Vásquez, C. 2016. Abriendo la autopoiesis: implicancias para el estudio de la comunicación organizacional. OPENING AUTOPOIESIS: IMPLICATIONS FOR THE STUDY OF ORGANIZATIONAL COMMUNICATION Cinta moebio 56: 136-146 doi: 10.4067/S0717-554X2016000200002

[6] H. Maturana; F. Varela. El árbol del conocimiento. Octava Edición. Santiago de Chile. Editorial Universitaria. 1992. 172 p.

[7] H. Maturana, H. Emociones y lenguaje en educación y política. Sexta edición Editorial universitarias. 1992. ISBN: 956-201-087-1

[8] F. Flores. W. Terry. Hacia la comprensión de la informática y la cognición. Ordenadores y conocimiento para el diseño del siglo XXI. Barcelona. Editorial Hispano Europea. S.A. 1989. 266 p.

[9] Xin, Yin. as teorías de los actos de habla. Una sinopsis. Centro internacional de pos grado. Universidad de Oviedo. Maestría. 2015.

[10] J. Psotka. Immersive tutoring system: virtual reality and education and formatiom. 1995. 31 Jan. http://205.130.63/its.html.

[11] T. Koulopoulos. C. Frappaolo, C. Smart things to know about knowledge management. Oxford: Capstone Publishing. 1999.

[12] Fialho, F,. Et. Al. (2007). Emprendedorismo na era do conhecimento. 2da . Impresión. Florianópolis - SC . Visual Books Ltda. 188 p. ISBN: 85-7502-180-X

[13] P. Scnge, Peter.La quinta disciplina : El arte y la práctica de la organización abierta al aprendizaje . - 2 ed. 10 Reimp. - Buenos Aires : Granica, 2010. ISBN 978-950-64 M306
[14] Verden-Zöller, Gerda. El juego en la relación materno infantíl: Fundamento biológico de la conciencia de si mismo y de la conciencia social. In: Amor y Juego. Fundamentos olvidados de lo humano. Maturana, Humberto R. e Verden-Zöller, Gerda. Santiago de Chile: Editorial Instituto de Terapia Cognitiva, 1994. p. 71-136. ISBN: 956-7344-01-9.

[15] Piaget, Jean. Gréco, Pierre. Aprendizagem e Conhecimento. Rio de Janeiro, Freitas Bastos, 1974.

[16] Vygotsky, Lev Semenovictch. A Formação Social da Mente: o desenvolvimento dos processos psicológicos superiores. $2 \mathrm{a}$ ed. São Paulo. Martins Fontes. 1994.

[17] A. Woolfolk E. Psicologia educativa. Sexta edición. Mexico: Prentice Hall Hispanoamericana S.A., 1996. 642 p. ISBN: 968-880-689-7

[18] I. Shor. Educations is politics. Paulo Freire's critical pedagogy. New York. Edited by Peter McLaren and Peter Leonard. 1993. p. 25-35.

[19] Watzlawick, P. (Ed.) (1981) Die Erfundene Wirklichkeit. Munich: Piper

[20] Roussos, M. Johnson, A. Leigh, J. Vasilakis, C. Constructing collaborative histories within virtual learning landscapes. 1996. Http://www.Ice.eecs.uic.edu/NICE/PAPERS/EUROAIED/HTML/aied.html

[21] Bruckman, Amy. Resnick, Michel. The Media MOO project: constructionism and professional community. 1995. Http://asb.www.media.mit.edu/peple/asb/convergence.html

[22] W. Winn. A conceptual basis for educational aplications of virtual reality. 1993. http://www.hitl.washington.edu/projects/education/winn/winnR-93-9.txt

[23] H. Maturana. Biology of cognition. Biological Computer Laboratory Research Report BCL 9.0. Urbana IL: University of Illinois, 1970. http://www.enolagaia.com/M70-80BoC.html

[24] J. Psotka. Immersive formatiom systems: immesion in virtual reality and formatiom. 1996 - 31 Jan: http://205.130.63.7/vrFormatiom.html

[25] P. Drucker. Llega una nueva organización a la empresa. Harvard Business Review. Gestión del Conocimiento. Ediciones Deusto: Bilbao. 2003 P.1-22.. ISBN: 84-234-2023-2003

[26] I. Nonaka. La empresa creadora del conocimiento. Harvard Business Review. Gestión del Conocimiento. Ediciones Deusto: Bilbao. 2003. P. 23-50. ISBN: 84-234-2023-2003

[27] Nonaka, I. and Takeuchi, H. The knowledge creating company: How Japanese companies create the dynamics of innovation. Oxford: Oxford University Press. 1995.

[28] K. Koskinen. P. Pihlanto, H. Vanharanta.Tacit knowledge acquisition and sharing in a project work context. International journal of project management. Vol. 21, pp. 281-290. 2003

[29] P. Senge. A Quinta disciplina: arte, teoria y pratica da organização da aprendizagen. São Paulo. Ed. Best Seller, 1990.

[30] L. Alfaro, "Contribuições para a modelagem de um ambiente inteligente de educação baseado em realidade virtual," Doutorado. Programa de Pós-Graduação em Engenharia de Produção. Universidade Federal de Santa Catarina, Brasil, 1999.

[31] M.-S. Yoh, "The reality of virtual reality," in In Proceedings Seventh International Conference on Virtual Systems and Multimedia, IEEE, 2001.

[32] M. Gonzales- Franco. J. Lanier. Model of Illusions and Virtual Reality. Review Article. Front. Psychol., 30 June 2017. https://doi.org/10.3389/fpsyg.2017.01125

[33] J. Psotka, "Immersive formatiom systems: Virtual reality and education and formatiom," Instructional science, vol. 23, no. 5, p. 405-431, 1995.

[34] J. Psotka, "Educational games and virtual reality as disruptive technologies," Journal of Educational Technology \& Society, vol. 16, no. 2, p. $69-80,2013$.

[35] J. Juang, W. Hung and S. Kang, "Simcrane 3d+: A crane simulator with kinesthetic and stereoscopic vision," Advanced Engineering Informatics, vol. 27, no. 4, p. 506-518, 2013.

[36] B. Zohra, G. Fabrice, R. Paul, B. Julien and P. Fabien, "An Overview of Interaction Techniques and $3 D$ Representations for Data Mining," Applications of Virtual Reality, p. 185, 2012.

[37] R. Linares, "Exploración de artículos científicos con realidad virtual y procesamiento del lenguaje natural," Maestría en Ing. Informática. Escuela de Posgrado. Universidad Nacional de San Agustín de Arequipa., 2017. 
[38] S. Dübel, M. Röhlig, H. Schumann and M. Trapp, "2d and $3 d$ presentation of spatial data: A systematic review," in In 2014 IEEE VIS International Workshop on 3DVis (3DVis), 2014.

[39] L. Freina. M. Ott. A literature review on immersive virtual reality in education: State of the art and perspectives. Conference: eLearning and Software for Education (eLSE), At Bucharest (Romania), 2015.

[40] K. Wanarat and T. Nuanwan, "Using 3d visualisation to improve public participation in sustainable planning process: Experiences through the creation of koh mudsum plan, thailand," Procedia-Social and Behavioral Sciences, vol. 91, p. 679-690, 2013.

[41] N. Menck, X. Yang, C. Weidig, C. Winkes, C. Lauer, H. Hagen, B Hamann and J. Aurich,"Collaborative factory planning in virtual reality," Procedia CIRP, vol. 3, p. 317-322, 2012.

[42] Place illusion and plausibility can lead to realistic behaviour in immersive virtual environments. The Royal Society, pp. 3549-3557. 2009 https://doi.org/10.1098/rstb.2009.0138

[43] Olguín Carbajal, Mauricio; Rivera Zarate, Israel; Pozas Quiteria, Oliver Desarrollo de un sistema inmersivo de realidad virtual basado en cabina multipersonal y camino sin fin. Polibits, núm. 37, pp. 79-82. 2008. Recuperado de http://www.scielo.org.mx/scielo.php?script=sci_arttext\&pid $=\mathrm{S} 1870-90442008000100011$

[44] E. Lombardo, S. Agostinelli and M. Metge, "Could an interactive and total immersive device with hmd improve memory and give the presence sensation?," Issues in Information Systems, vol. 14, p. 315-321, 2013.

[45] D. Wigdor and D. Wixon, ” Brave NUI world: designing natural user interfaces for touch and gesture", Elsevier, 2011.

[46] N. Villaroman, D. Rowe and B. Swan, "Teaching natural user interaction using openni and the microsoft kinect sensor," in In Proceedings of the 2011 conference on Information technology education, 2011.

[47] G. Calle, E. Castro-Gutierrez and L. Alfaro, "Virtual Rehabilitation Using Sequential Learning Algorithms," International Journal of Advanced Computer Science and Applications (IJACSA), vol. 9, no. 11, 2018.

[48] A. Cámara, "Natural user interfaces," in In IFIP Conference on HumanComputer Interact, 2011.

[49] S. Mann,” Intelligent image processing”, John Wiley \& Sons, 2001.

[50] W. Winn. A conceptual basis for educational aplications of virtual real- ity.1993. http://www.hitl.washington.edu/projects/education/winn/winnR-93-9.txt

[51] P. Thi Hoa and H. Ying-Yuh, "The Impact Of Experiential Marketing On Customer's Experiential Value And Satisfaction: An Empirical Study In Vietnam Hotel Sector," Journal of Business Management \& Social Sciences Research, vol. 4, no. 1, 2015.

[52] H. Maturana. Refexiones: Aprendizaje o deriva ontogénica. In: Desde la biología a psicologia. Santiago de Chile: Editorial Mitech Ltda. Ediciones Synthesis, 1993. p. 82-102. ISBN: 956-7335-01-X

[53] B. Bottge, Et al. Impact of Enhanced Anchored Instruction in Inclusive Math Classrooms. Exceptional Children. 2015, Vol. 81(2) 158-175 (C) 2014 The Author(s) DOI: 10.1177/0014402914551742 ec.sagepub.com

[54] PROJECT-BASED LEARNING HANDBOOK Educating the Millennial Learner". FIRST EDITION: SEPTEMBER 2006 Copyright (c) 2006 Educational Technology Division, Ministry of Education. Kuala Lumpur: Malaysia. ISBN: 983-3244-31-9

[55] J. Flores. P. Camarena Gallardo, E. ávalos .La realidad virtual, una tecnología innovadora aplicable al proceso de enseñanza de los estudiantes de ingeniería. Revista Apertura, vol. 6, núm. 2. 2014. Recuperado de http://www.udgvirtual.udg.mx/apertura/index.php/apertura/ article/view/547/369

[56] M. Roussou.Learning by doing and learning through play: an exploration of interactivity in virtual environments for children. Computers in Entertainment (CIE), 2(1), 10-10. (2004)

[57] Garris, R., Ahlers, R., \& Driskell, J. E. (2002). Games, motivation, and learning: A research and practice model. Simulation \& gaming, 33(4), 441-467.

[58] Ott, M., \& Tavella, M. (2009). A contribution to the understanding of what makes young students genuinely engaged in computer-based learning tasks. Procedia-Social and Behavioral Sciences, 1(1), 184-188.

[59] C. Carol. Learning styles in Higher Education. A case study in History formatiom The 6th International Conference Edu World 2014 "Education Facing Contemporary World Issues", 7th - 9th November. Procedia Social and Behavioral Sciences 180 ( 2015 ) 256 - 261

[60] S. La Valle. Virtual Reality. University of Oulu. Cambritch University Press. 2019. Availablefordownloadingathttp://vr.cs.uiuc.edu/

[61] J. Psotka. Davison, Sharon Cognitive factors associated with immersion in virtual environments. 1996a- 29 Abril. http://205.130.63.7/vrfopub.htm 